\title{
Erratum to: Characteristics of stepfamilies and maternal mental health compared with non-stepfamilies in Japan
}

Masako Sugimoto* and Yoshie Yokoyama

\section{Erratum}

After the publication of this article [1] it has come to our attention that the ethical approval receipt number of this study was not included in the article. As such, please note that this study [1] was approved by the Ethics Committee of Osaka City University (receipt no. 27-8-1).

Received: 5 June 2017 Accepted: 7 June 2017

Published online: 16 June 2017

\section{Reference}

1. Sugimoto, Yokoyama. Characteristics of stepfamilies and maternal mental health compared with non-stepfamilies in Japan. Environ Health Prev Med. 2017;22:1. doi:10.1186/s12199-017-0658-z.

\footnotetext{
* Correspondence: sugimotom_417@yahoo.co.jp 